\title{
DESENVOLVIMENTO COMO JUSTIÇA EM ARISTÓTELES, KANT, RALWS, DWORKIN E SEN: contribuições para a construção de um significado objetivo para a teoria do desenvolvimento
}

Eline Débora Teixeira ${ }^{1}$

RESUMO: Esta pesquisa constrói uma definição objetiva para a teoria do desenvolvimento, no âmbito do direito, em detrimento da clássica e utilitarista abordagem econômica. Desenvolve-se uma releitura dessa teoria cuja racionalidade seja justiça, com base em Aristóteles, Rawls, Dworkin e Amartya Sen. Metodologicamente, a técnica de pesquisa é teórica, o método de abordagem é dialético e o método de procedimento é monográfico. $\mathrm{O}$ objetivo é demonstrar que a teoria da justiça no direito do ocidente levou à sua conexão com a teoria do desenvolvimento. Conclui-se que a teoria do desenvolvimento concebeu liberdade, igualdade e capacidade como seus definidores objetivos.

PALAVRAS-CHAVE: igualdade; liberdade; capacidade; equidade; desenvolvimento.

\section{DEVELOPMENT AS JUSTICE IN ARISTÓTELES, KANT, RALWS, DWORKIN AND SEN: contributions towards the construction of an objective meaning for development theory}

\begin{abstract}
This research constructs an objective definition for the theory of development, in the scope of the law, to the detriment of the classic and utilitarian economic approach. A rereading of this theory, whose rationality is justice, is based on Aristotle, Rawls, Dworkin, and Amartya Sen. Methodologically, the research technique is theoretical, the approach method is dialectical and the procedure method is monographic. The aim is to demonstrate that the theory of justice in Western law has led to its connection with development theory. We conclude that development theory has conceived of freedom, equality, and capacity as its objective definers.
\end{abstract}

KEY WORDS: equality; freedom; capacity; equity; development.

\section{INTRODUÇÃO}

A presente pesquisa busca uma definição objetiva para a teoria do desenvolvimento, sob a perspectiva do sistema do direito, que não limite a sua conceituação em desenvolvimento apenas econômico, social, tecnológico, científico, humano, dentre outros, mas que a integre

\footnotetext{
${ }^{1}$ Mestranda em Direito pela Universidade Federal de Uberlândia. Pós-graduada em Direito e Processo do Trabalho pelo Centro Universitário de Patos de Minas - UNIPAM. Graduada em Direito pelo Centro Universitário de Brasília - UniCeub. Endereço eletrônico: elinedeborah@gmail.com. Endereço postal: Rua José dos Reis, nº 197, Patos de Minas, CEP: 38700-180.
} 
para uma racionalidade comum, a fim de tratar o fenômeno do desenvolvimento em sua completude.

A teoria do desenvolvimento classicamente tem sido estudada pela ótica do sistema da economia, por vezes com sua racionalidade utilitarista, incorrendo em uma visão parcial do fenômeno do desenvolvimento, portanto limitada e incompleta. Propomos aqui uma releitura da teoria do desenvolvimento que transpasse a lógica meramente utilitarista, partindo do sistema do direito, mas que leve em consideração os diversos sistemas inter e transdisciplinares, cuja finalidade seja necessariamente a justiça.

Trabalhar a teoria do desenvolvimento sob a referência do sistema do direito significa, sobretudo, buscar, por meio dessa teoria, a racionalidade do direito, qual seja, a justiça. Nesse sentido, procura-se fazer uma releitura da teoria da justiça e seus principais representantes, quais sejam, Aristóteles ${ }^{2}$, Ralws ${ }^{3}$, Dworkin ${ }^{4}$ e Amarthya Sen $^{5}$, colocando-a como referência para a formulação de um significado objetivo para a teoria do desenvolvimento.

Nesse contexto, a presente pesquisa utiliza-se da técnica de pesquisa teoria, do método de abordagem dialético, uma vez que serão abordadas diversas teorias da justiça como base para se conceber um significado objetivo para a teoria do desenvolvimento. O método de procedimento será o monográfico, com base no levantamento de referências bibliográficas e documentais, consistentes em artigos científicos, livros, relatórios de órgãos oficiais e estudos científicos diversos relacionados ao objeto de pesquisa.

O objetivo geral da presente pesquisa consiste em analisar como o desenvolvimento da teoria da justiça no sistema do direito no mundo ocidental levou à sua conexão necessária com a formulação de uma teoria do desenvolvimento, uma vez que considerou tanto os diversos subsistemas do sistema social ${ }^{6}$, bem como os diversos olhares sobre o desenvolvimento (social,

\footnotetext{
${ }^{2} \mathrm{O}$ autor desenvolve sua teoria da justiça principalmente na seguinte obra: ARISTÓTELES. Ética a Nicômaco. In: ARISTÓTELES. Tópicos, Dos argumentos sofísticos, Metafísica, Ética a Nicômaco, Poética. Tradução de Leonel Vallandro e Gerd Bornheim. São Paulo: Abril Cultural, 1973. P. 245-442.

${ }^{3} \mathrm{O}$ autor desenvolve sua teoria da justiça principalmente na seguinte obra: RAWLS, John. Uma teoria da justiça. Tradução: Jussara Simões. Revisão técnica e da tradução: Álvaro de Vita. São Paulo: Martins Fontes, 2016.

${ }^{4} \mathrm{O}$ autor desenvolve sua teoria da justiça principalmente na seguinte obra: DWORKIN, Ronald. A virtude soberana: a teoria e prática da igualdade. São Paulo: Martins Fontes, 2016.

${ }^{5} \mathrm{O}$ autor desenvolve sua teoria da justiça principalmente na seguinte obra: SEN, Amartya. A ideia de justiça. Tradução: Denise Bottmann e Ricardo Doninelli Mendes. São Paulo: Companhia das Letras, 2011.

${ }^{6}$ Luhmann formula uma teoria que considera a sociedade moderna como um sistema social, marcada por diferentes funções, que se manifestam na forma de subsistemas (economia, política, ciência, direito). Assim, para Luhmann, o sistema é sempre fechado para operar internamente, diferenciando-se de tudo mais que não seja ele próprio e definindo-se a partir de sua diferença em relação ao entorno. Uma característica dos sistemas é reduzir a complexidade, dada sua função de sempre reduzir possibilidades a partir da seleção daquilo que terá sentido para o sistema quando incorporado aos processos internos. Quando atingem um elevado nível de complexidade, os sistemas produzem autonomias relativas, diferenciando-se, com o objetivo de reduzir essa complexidade. Toda
} 
econômico, tecnológico, científico e humano), gerando a possibilidade e necessidade de formulação de um significado objetivo para a teoria do desenvolvimento.

Apresentar um significado objetivo para a teoria do desenvolvimento constitui uma tarefa importante para os estudos da teoria do desenvolvimento sob a ótica do sistema do direito, ou, sobre estudos de direito e desenvolvimento, que estão hoje sem limites conceituais. Do artigo de Trubek e Galanter (2007), "Scholars in Self-Estrangement" ao mais recente "Desenvolvimento como Liberdade" de Amartya Sen (2000), estudiosos discutiram a teoria do desenvolvimento em diferentes contextos.

É porque a teoria do desenvolvimento não possui uma definição que é universalmente aceita, embora tenha sido geralmente entendida como mudanças sociais, políticas e econômicas progressivas nos países em desenvolvimento. Assim, faz-se necessária a definição de um significado objetivo para a teoria do desenvolvimento sob a ótica do direito, que será produzida no âmbito desta pesquisa com base na teoria da justiça, por ser a racionalidade do sistema do direito.

\section{DESENVOLVIMENTO COMO JUSTIÇA EM ARISTÓTELES}

Aristóteles foi um filósofo grego, nascido em meados de 384 a. C., e, em seu livro, “Ética a Nicômacos”, mais especificamente no capítulo V, desenvolveu uma teoria da justiça que influenciou todo o sistema do Direito do mundo ocidental. Aborda-se, neste tópico, a teoria da justiça aristotélica, no tocante à vantagem oferecida à área pública para construir a equidade nas relações sociais e políticas, criando fundamentos de justiça que consideram a liberdade, a igualdade, a diferença, a reciprocidade e a legalidade, a partir de um padrão procedimental que usa uma orientação moral para o ordenamento político, sem fazer uma integral diminuição do ambiente da moralidade pública ao espaço da moralidade privada.

$\mathrm{Na}$ sequência, passa-se à construção de um paralelo entre a teoria da justiça de Aristóteles e a teoria do desenvolvimento, a fim de conceber um significado objetivo para esta. Pretende-se apontar, com base na filosofia prática aristotélica, o estabelecimento de um modelo ético complementar, em que se encontra a validade das virtudes (seara particular) e dos princípios (seara pública) como critérios morais, também instituidores de uma nova teoria do desenvolvimento, e não apenas da justiça.

diferenciação implica, portanto, redução de complexidade. RODRIGUES, Leo Peixoto; NEVES, Fabrício Monteiro. Niklas Luhmann: a sociedade como sistema. Porto Alegre: Edipucrs, 2012, p. 91. 
Aristóteles, em "Etica a Nicômacos” (1973. p. 245-442), no capítulo V, desenvolve sua teoria da justiça na qual considera a justiça como uma virtude completa. Isso significa que a justiça está sendo considerada como uma virtude ética, e que o termo "justiça” é utilizado em dois sentidos. O indivíduo injusto seria o que transgrida a lei, sendo, também, não equitativo. Assim, Aristóteles já identifica uma confusão linguística no uso da expressão justiça, apresentando dois sentidos: ações justas, pertencentes ao campo da moral (seara individual/privada), e igualdade na distribuição de bens da comunidade política (seara pública) (SILVEIRA, 2007).

Nesse contexto, Aristóteles já fazia a sutil diferenciação entre a esfera do que é a moral privada e do que é a moral pública. Quando a palavra "justiça” é entendida como o que pudesse considerar como esfera privada, justo é o que a moral considera correto. Quando o termo "justiça" é compreendido como sinônimo de igualdade, o vício correspondente é ter mais que a parte devida. Assim, é possível conectar a esfera pública com a esfera particular, na teoria da justiça de Aristóteles, quando se considera que a justiça geral, da seara pública, é uma virtude inteira, e que a justiça particular é uma virtude que compõe a virtude inteira, para formar a justiça geral (SILVEIRA, 2007).

Fazendo um paralelo com a teoria do desenvolvimento, uma afronta a essa teoria, sendo chamada de ausência de desenvolvimento, também seria, na seara individual, ilegal, e na seara pública, desigual. Por exemplo, um indivíduo que não possui condição de acesso à educação e que não possui vontade de acesso à educação, sofre, na esfera individual, uma ausência de desenvolvimento (humano) que é ilegal, e na esfera pública, uma ausência de desenvolvimento (social) que é desigual com relação aos seus pares.

Tem-se, então, a identificação da justiça e do desenvolvimento com o ordenamento político-jurídico que estabelece critérios mais fortes para a convivência societária do que somente a deliberação subjetiva do indivíduo. Isso significa que a justiça, bem como o desenvolvimento proposto aqui, não tratará do aspecto legal-moral e, sim, do aspecto equitativo, no entanto, aquilo que fere a equidade é também ilegal. $\mathrm{O}$ objeto central da teoria da justiça e da teoria do desenvolvimento é a garantia de equidade nas relações públicas da comunidade política.

No que diz respeito à educação do indivíduo enquanto tal (faceta da teoria do desenvolvimento correspondente ao desenvolvimento humano), para Aristóteles, a questão central para a teoria da justiça não se encontra na formação do bom ser humano, mas na 
formação do homem enquanto cidadão. O que Aristóteles conclui é que não existe uma identidade absoluta entre um bom ser humano e um bom cidadão, significando que a esfera pública de justiça não necessita de uma visão perfeita de homem para o estabelecimento de critérios a respeito da equidade na sociedade política, a justiça podendo ser alcançada por cidadãos e não necessariamente homens virtuosos (1973. p. 245-442).

No mesmo sentido está a teoria do desenvolvimento proposta aqui, que não exige um ser humano com valor de bondade, ou de qualquer outra virtude correspondente ao âmbito particular, e sim um bom cidadão. Assim, essa diferenciação é importante, pois o desenvolvimento humano relaciona-se diretamente com a formação do bom cidadão, que possui cognição para a vida em sociedade, demonstrando assim a compatibilidade da teoria do desenvolvimento proposta aqui com a teoria da justiça de Aristóteles (SILVEIRA, 2007).

Ao desenvolver a justiça distributiva, Aristóteles apontará qual forma de mediania equivalha ao ato justo, no qual se deve identificar de qual maneira se realiza essa atividade, se do mesmo modo que as outras virtudes, ou se utiliza de algum mecanismo diferente. Mostra que, com relação aos bens públicos que serão distribuídos, a injustiça consiste na não equidade, isto é, na desigualdade, existindo o mais e o menos e, portanto, o justo será a mediania entre o mais e o menos, isto é, o igual (SILVEIRA, 2007).

Nesse sentido, Aristóteles percebe que a justiça envolve muitos elementos, por exemplo, dois indivíduos para os quais existe a justiça e duas proporções que são justas. A regra da justiça distributiva pauta-se na igualdade, que deve ser proporcional, de forma que a proporção entre as parcelas de bens a serem distribuídas deve corresponder à proporção entre os indivíduos, concluindo-se que, se os indivíduos não forem iguais, receberão porções diferentes dos bens. Com base nisso, Aristóteles formula o Princípio da Diferença ${ }^{7}$.

Esse princípio da diferença é formulado a partir de uma compreensão do que é a distribuição equitativa dos bens públicos, fundamentada em um critério matemático de igualdade, com proporção geométrica, por meio de um procedimento racional para designar o

\footnotetext{
${ }^{7}$ Aristóteles cria, então, um procedimento para a realização da justiça distributiva, qual seja: identificação do bem, consistente na distribuição dos bens públicos; fundamentação do princípio de justiça, consistente no critério matemático de igualdade; a igualdade envolve dois termos, significando que o justo seja uma mediania e igual, sendo relativo ao que é justo para determinados indivíduos e como uma mediania, coloca-se entre o mais e o menos, como igual, implica duas proporções que são iguais, como justo, envolve determinados indivíduos em relação aos quais é justo; conclui-se que a justiça envolve proporções, uma vez que, para dois indivíduos para os quais existe a justiça existirá também duas proporções que são justas; formulação do princípio da diferença: a regra da justiça distributiva é formulada como uma igualdade proporcional, de maneira que a proporção entre as parcelas de bens públicos deve ser correspondente à proporção entre os indivíduos.
} 
que é o justo (igualdade proporcional). A justiça distributiva é independente do entendimento individual do indivíduo moral que a utilizará para fundamentar sua ação. Isso constitui a base da doutrina eudemonista das virtudes de Aristóteles, utilizando, ao invés da subjetividade que tem a norma como referência, um critério objetivo para a determinação do justo, tendo um sentido público que se distancia de um modelo de racionalidade prática privada (1973. p. 245442).

Atribuir um significado objetivo para a teoria do desenvolvimento, quando estruturada com base na teoria da justiça aristotélica, significa exatamente isso, determinar para o desenvolvimento um sentido público, que se distância de qualquer modelo praticado individualmente. Nesse contexto, a teoria do desenvolvimento proposta nesta pesquisa comporta o desenvolvimento distributivo, consistente no mesmo modelo procedimental proposto por Aristóteles para a justiça distributiva, condizente também com o princípio da diferença.

A segunda espécie de justiça equitativa desenvolvida por Aristóteles é a justiça corretiva, que se manifesta nas relações privadas, tanto nas relações voluntárias, âmbito do direito civil, como nas relações involuntárias, âmbito do direito penal. Essa justiça opera com o critério da proporção aritmética, na qual o fundamento continua sendo o da igualdade, porém ela não segue a proporção geométrica, pois o que é fundamental nesse tipo particular de justiça é restabelecer a igualdade que foi rompida de forma universal.

A justiça corretiva de Aristóteles conecta-se à teoria do desenvolvimento, de maneira que, na formulação do desenvolvimento corretivo, todos os indivíduos são iguais perante a lei, portanto, suas qualidades morais são também irrelevantes para a aferição da sua parcela de direito ao desenvolvimento corretivo.

Aristóteles identifica um terceiro tipo de justiça particular, qual seja, a justiça como reciprocidade (comercial) cujo critério essencial é a reciprocidade proporcional, visando à garantia da união da polis nas trocas comerciais, corroborando com o argumento de que a teoria da justiça não está sendo desenvolvida na esfera da ética das virtudes (1973. p. 245-442).

Aristóteles não concorda com a equivalência do critério de reciprocidade proporcional com a justiça universal, fundamentada em um tratamento igualitário baseado em fazer a " $\mathrm{A}$ " aquilo que ele fez a "B", da maneira que era formulada pela escola pitagórica. Nesse sentido, Aristóteles também não considera possível relacionar o critério de reciprocidade com a justiça distributiva e nem com a justiça corretiva. Aristóteles somente admite o critério da 
reciprocidade proporcional nas trocas meramente comerciais, para o fim de possibilitar a união da polis (BROADIE, 2002, p. 37).

A análise da teoria da justiça de Aristóteles revela a possibilidade de encontrar em sua ética um modelo complementar entre virtudes (esfera privada) e princípios (esfera pública). No entanto, essa complementaridade não significa uma redução dos princípios de justiça à moralidade privada, mas, possibilita identificar a relevância da ética na esfera política-jurídica.

No mesmo sentido está a teoria do desenvolvimento, na qual o desenvolvimento natural serve de orientação para o desenvolvimento legal, mas não reduz o desenvolvimento à moral, pois o desenvolvimento legal é construído no espaço deixado em aberto pelo desenvolvimento natural, que é igualmente modificável.

Também a responsabilidade individual, o ato voluntário para deliberar e escolher é requisito importante para o completo desenvolvimento individual, porém, o desenvolvimento individual não é igual ao ato moral de desenvolvimento individual (ou à vontade moral de desenvolvimento individual), porque o indivíduo pode querer para si algo contrário ao desenvolvimento individual, que possui um conceito objetivo, pensando estar agindo conforme, e não estar.

A virtude da equidade serve como corretora do desenvolvimento legal e isso implica pensar em um procedimento de equilíbrio reflexivo, em que o sujeito moral deve corrigir a generalidade da lei para determinar o que é correto na ação particular.

Portanto, a teoria da justiça aristotélica pode ser utilizada como diretriz para a formulação objetiva de uma teoria do desenvolvimento, que privilegia a esfera pública para estabelecer a equidade nas relações sociais e políticas, instituindo princípios de desenvolvimento que respeitam a liberdade, a igualdade, a diferença, a reciprocidade e a legalidade, a partir de um modelo procedimental que utiliza uma referência moral (pública) para o ordenamento político, sem realizar uma completa redução da esfera da moralidade pública à esfera da moralidade privada.

Nesse contexto, é possível apontar, com base na filosofia prática aristotélica, um modelo complementar entre a teoria da justiça e a teoria do desenvolvimento, em que se encontra a validade das virtudes (esfera privada) e dos princípios (esfera pública) como critérios morais, definidores de uma teoria do desenvolvimento, em seus vieses tanto substancial como procedimental. 


\section{DESENVOLVIMENTO COMO JUSTIÇA EM RALWS}

John Rawls, em "Uma teoria da justiça", traz uma nova reflexão sobre a concepção de justiça, por meio de sua filosofia política. Rawls é considerado um contratualista ${ }^{9}$, como Locke $^{10}$, Rousseau ${ }^{11}$ e Kant ${ }^{12}$, em que pese existirem diferenças e semelhanças em suas concepções. No capítulo inicial, chamado "Justiça como equidade", Rawls apresenta a sua concepção de justiça e tenta diferenciá-la do utilitarismo ${ }^{13}$ de Bentham $^{14}$ e Mill ${ }^{15}$. O filósofo americano define sua teoria como deontológica ${ }^{16}$, o que é o oposto da tradição teleológica, de Aristóteles, que visa atingir um fim ou objetivo.

Rawls parte de uma concepção geral de justiça que se baseia na ideia de que todos os bens sociais primários, como liberdades, oportunidades, riqueza, rendimento e as bases sociais da autoestima devem ser distribuídos de maneira igualitária, exceto no caso de uma distribuição desigual de alguns ou de todos os bens for mais benéfica às pessoas da sociedade. Para Rawls, tratar as pessoas como iguais não significa remover todas as desigualdades, mas apenas aquelas que contribuem para desvantagens a uma das partes do contrato. Destinar mais dinheiro a uma

\footnotetext{
${ }^{8}$ RAWLS, John. Uma teoria da justiça. Tradução: Jussara Simões. Revisão técnica e da tradução: Álvaro de Vita. São Paulo: Martins Fontes, 2016.

${ }^{9}$ Contratualismo é uma corrente filosófica que tenta explicar a importância da construção das sociedades. De maneira geral, o contrato social ou contratualismo constitui um acordo firmado entre os cidadãos de uma sociedade. Dessa forma, os indivíduos abdicam de alguns direitos ou liberdades para que possam organizar um governo, em busca de segurança e estabilidade. Neste contexto, surge o compromisso coletivo de obedecer às normas estabelecidas pelo governo, assim como também este deve cumprir suas obrigações.

${ }^{10}$ A principal obra sobre o contratualismo de Locke pode ser considerada a seguinte: LOCKE, J. "Segundo Tratado sobre o Governo". Traduções de Anoar Aiex e E. Jacy Monteiro, $3^{\text {a }}$ ed. São Paulo: Abril Cultural, 1983.

${ }^{11}$ A principal obra sobre o contratualismo de Rousseau pode ser considerada a seguinte: ROUSSEAU, Jean Jacques. O contrato social. São Paulo: Cultrix, 1989.

${ }^{12}$ Uma das principais obras nas quais Kant desenvolve a ideia de contratualismo pode ser considerada a seguinte: KANT, Immanuel. À paz perpétua. Trad. Marco Zingano. Porto Alegre, RS: L\&PM, 2010.

${ }^{13} \mathrm{O}$ utilitarismo é uma doutrina ética defendida principalmente por Jeremy Bentham e John Stuart Mill que afirma basicamente serem boas as ações quando tendem a promover a felicidade e más quando tendem a promover o oposto da felicidade.

${ }^{14}$ A principal obra sobre o utilitarismo de Bentham pode ser considerada a seguinte: BENTHAM, Jeremy. Uma introdução aos princípios da moral e da legislação. $2^{\mathrm{a}}$ ed. Trad. Luiz João Baraúna. São Paulo: Abril Cultural, 1979.

${ }^{15}$ A principal obra sobre o utilitarismo de Mill pode ser considerada a seguinte: MILL, John Stuart. Utilitarianism. Auckland, New Zealand: The Floating Press, 2009.

${ }^{16}$ Deontologia ou ciência do dever, na filosofia moral contemporânea, é uma das teorias normativas, segundo a qual as escolhas são moralmente necessárias, proibidas ou permitidas. Portanto inclui-se entre as teorias morais que orientam as escolhas sobre o que deve ser feito. A proposta de justiça como equidade enquanto política é compatível com o ideal deontológico. Se os utilitaristas admitem que o conceito de bem seja definido de forma independente do justo, o contratualismo rawlsiano é, simultaneamente, um contraponto a este modelo e uma tentativa de retomar o modelo deontológico kantiano transposta em termos de prioridade do justo sobre o bem. BARBOSA, Evandro. Deontologia imparcial contratualista: sobre a possibilidade de um procedimento autojustificado para a construção de princípios de justiça. Orientador: Thadeu Weber. Tese (Doutorado em Filosofia), Programa de Pós-Graduação em Filosofia, PUCRS, Porto Alegre, 2011.
} 
parte em relação à outra pode promover um maior interesse de ambas as partes. Nesse caso, a igualdade dos interesses não proíbe um tratamento desigual para cada parte.

Rawls, ao construir a sua teoria da justiça, problematiza a sociedade a partir de uma ótica deontológica. Assim, Rawls extrai basicamente dois princípios. O primeiro princípio determina que cada pessoa deve ter direito igual ao mais abrangente sistema de liberdades básicas iguais, que seja compatível com um sistema semelhante de liberdades para as outras. $\mathrm{O}$ segundo princípio aduz que as desigualdades sociais e econômicas devem ser ordenadas de tal modo que sejam, ao mesmo tempo, consideradas como vantajosas para todos dentro dos limites do razoável e vinculadas a posições e cargos acessíveis a todos (2016, p. 75).

$\mathrm{Na}$ posição original, cobertos pelo véu da ignorância, indivíduos livres, iguais, racionais e interessados acordam sobre quais princípios de justiça devem governar a estrutura básica da sociedade. Assim, Rawls pretende apresentar os princípios da justiça estabelecidos de forma a assegurar a justiça como equidade. Como na posição original, as partes acordantes possuem o mesmo peso no ato da deliberação e escolha dos princípios, cada um pode fazer propostas, apresentar razões para a sua aceitação e assim por diante (2016, p. 76).

Segundo Rawls, três contingências afetam diretamente as perspectivas de vida dos cidadãos, provocando as desigualdades que ficam de fora no ato da formulação dos seus dois princípios de justiça. Essas contingências são: a classe social de origem das pessoas; os talentos naturais (em contraposição aos talentos adquiridos), juntamente com as oportunidades que têm de desenvolver esses talentos em função de sua classe social de origem; a boa ou má sorte ao longo da vida (como são afetados pela doença, acidentes, desemprego involuntário, declínio econômico regional, dentre outros) (2016, p. 77).

As pessoas na posição original não têm informação sobre qual geração pertencem. Assim, Rawls acredita que pelo fato dos indivíduos estarem cobertos pelo véu de ignorância, ou seja, destituídos das informações apresentadas acima, sua teoria elimina privilégios de negociação, tornando a posição original equitativa (RAWLS, 2016, p. 21).

Para Rawls, o primeiro princípio, que destaca a liberdade, possui prioridade sobre o segundo. Nesse sentido, o segundo princípio ainda é desdobrado em dois, quais sejam, o princípio da igualdade de oportunidades e o princípio da diferença. A prioridade do primeiro princípio sobre o segundo constitui uma forma apresentada por Rawls para determinar a primazia do justo sobre o bem. Assim, Rawls indica que sua teoria possui uma natureza que a afasta do utilitarismo (OLIVEIRA, 2013, p.254-291). 
No entanto, é preciso questionar por que é melhor que as pessoas estejam sob um véu da ignorância no ato de deliberação a respeito da justiça na sociedade, a real necessidade de resguardar a ignorância da pessoa para se pensar sobre justiça e quais demandas efetivas a teoria da justiça formulada a partir do véu da ignorância consegue abranger? Rawls responde essas questões, demonstrando que a posição original constitui o método mais adequado para se estabelecer justiça, pelo fato das pessoas serem livres e iguais. No entanto, não nos diz muito sobre ser realmente necessário resguardar a ignorância da pessoa para se pensar sobre justiça (ROUANET, 2002).

A teoria da justiça de Rawls contribui para a teoria do desenvolvimento, por meio dos dois princípios de justiça, que tratam principalmente da igualdade, da liberdade, da imparcialidade e do respeito ao outro para a vida em sociedade. No entanto, ignora algumas situações no âmbito privado dos indivíduos que podem influenciar diretamente na realização das teorias da justiça e do desenvolvimento, fundamentando tratamento diferenciado.

\section{DESENVOLVIMENTO COMO JUSTIÇA EM DWORKIN}

Ronald Myles Dworkin foi um filósofo do Direito norte-americano. Esse tópico destina-se à análise da teoria da justiça formulada por Dworkin, e também à leitura conexa dos fundamentos de justiça em Dworkin como instituidores de um significado objetivo para a teoria do desenvolvimento.

Dworkin faz uma crítica à teoria da justiça rawlseana, justamente pelo fato de que ela se baseia em uma situação hipotética, fora do campo da realidade, impedindo, assim, a realização de escolhas. Ao visitar a teoria da justiça de Rawls, Dworkin analisa primeiramente os princípios da justiça. Para o autor, é preciso reformular os princípios da justiça de Rawls para que os mesmos consigam atingir a normatividade contratual (DWORKIN, 2016, p. 158).

Para Dworkin, o contrato não constitui ponto de partida dos princípios de justiça, e sim instrumento para realização deles, um caminho para se chegar à justiça. Ademais, Dworkin não acredita que a estruturação dos princípios de justiça possam se dar de maneira arbitrária e consensual, ausente de intenção por trás desse arranjo hipotético (2014, p. 274).

Dworkin aceita o contrato como um bom instrumento para a realização da justiça. No entanto, considera irrelevante o conhecimento que os indivíduos têm sobre si mesmos na posição original para impedir imparcialidades. Além disso, Dworkin não concorda que o primeiro princípio de justiça de Rawls seja mais importante que o segundo. Uma vez que Rawls 
definiu a liberdade como o mínimo possível de restrições, não se sabe até que ponto a liberdade pode aumentar ou diminuir as chances de efetivação dos interesses particulares (DWORKIN, 2016, p. 452).

No entanto, para Dworkin, a igualdade decorre não do primeiro princípio de justiça, como pensava Rawls, mas de um pressuposto de existência da própria posição original. A partir dessa constatação, Dworkin legitima o uso de mecanismos mais inclusivos, tais como a discriminação positiva, visando à garantia do tratamento igual, com base em um estímulo desigual, quando não é possível uma igual consideração formal dos indivíduos em questão (DWORKIN, 2016, p. 543).

Por outro lado, Dworkin defende a adoção da igualdade de recursos como a melhor esfera a ser resguardada para a realização da justiça. A tese central oferecida por Dworkin é pautada pela distribuição equitativa dos recursos disponíveis. Dentre os aspectos oferecidos por sua teoria, Dworkin desenvolve a ideia de que as pessoas são responsáveis pelas escolhas que fazem em suas vidas, desenvolvendo seu projeto de justiça liberal. No entanto, Dworkin explica que esta premissa não é suficiente para uma distribuição justa de bens. Existem, segundo o autor, atributos naturais, tais como o talento e a inteligência, que influenciam a disposição dos recursos em determinada sociedade (2016, p. 453).

Dworkin retira o véu da ignorância que cobria o olhar do indivíduo para o mundo. Nesse sentido, o indivíduo passa a ocupar um lugar onde deseja realizar uma divisão justa dos recursos disponíveis. Então, Dworkin define e defende os critérios que determinarão a distribuição justa desses bens. Dworkin critica a posição utilitarista de justiça, com uma ideia inicial bastante semelhante àquela percorrida por Rawls, constatando que o bem estar nunca pode ser utilizado como o único critério para uma análise justa. Assim, Dworkin defende a igualdade de recursos pautada em dois princípios básicos: escolha e responsabilidade (OLIVEIRA, 2013, p.254-291).

Dworkin defende a sua teoria de igualdade de recursos por meio de uma situação hipotética, assim como Rawls. Nesse contexto, imagina uma ilha na qual um grupo de pessoas encontra-se em um local com recursos naturais suficientes para a sobrevivência de todos. No entanto, não se sabe a quantidade de tempo que as pessoas permanecerão neste lugar, e, assim, um acordo é feito, constando que ninguém possui direito prévio a nenhum dos recursos disponíveis. Com base nessas condições, Dworkin cria um modelo de divisão igualitária e legítima dos bens disponíveis em uma sociedade real (DWORKIN, 2016, p. 79). 
Mas como fazer com que essa divisão possua valor de justiça? Em seu livro, a "A virtude soberana" Dworkin finalmente desenvolve uma teoria igualitária de recursos. O autor defende que a virtude soberana de uma sociedade política constitui seu próprio caráter igualitário. A igualdade pensada nesse sentido não está fundamentada na liberdade apenas, mas, sobretudo, na disponibilidade de recursos que cada cidadão possui. $\mathrm{O}$ teste da cobiça é inserido por Dworkin com a finalidade de validar sua proposta, da seguinte forma: ao final da divisão dos recursos, se algum integrante preferir o bem adquirido por outro a divisão dos recursos não pode ser tida como igualitária.

É importante mencionar que Dworkin imagina uma variedade de recursos plenamente disponíveis para seus indivíduos numa ilha deserta, cuja sociedade é proveniente de um náufrago. Por essa razão, Dworkin supõe que cada indivíduo tem a posse de um número igual de conchas, que serão utilizadas como fichas para um leilão, um método que busca mensurar os recursos necessários para cada vida em particular, que serão diferentes (OLIVEIRA, 2013, p.254-291).

O leilão representa o mercado de bens disponíveis e a divisão dos recursos entre os participantes. Para Dworkin, não se pode confiar apenas nas leis do mercado para se alcançar um ideal de igualdade social. Isso porque, o mercado não observa um atributo a ser considerado pela teoria da justiça, qual seja, as condições individuais dos participantes detentores de recursos para aquisição dos bens disponíveis à compra (OLIVEIRA, 2013, p.254-291).

Nesse contexto, ao mercado competem apenas duas propriedades: o mecanismo de correção da desigualdade de recursos gerados a partir de escolhas individuais e o papel de demonstrar que o motivo da diferença de riquezas entre as pessoas não pode ser a diferença de talentos naturais, mas as contingências das escolhas de cada um. Assim, imaginando novamente a ilha, Dworkin assegura que um leilão de bens jamais daria certo se todos não dispusessem de uma mesma quantidade de conchas iniciais. Já no final do leilão, com o livre comércio, em pouco tempo, a igualdade de recursos será desfeita. Assim, Dworkin constrói outra importante teoria, a do seguro (DWORKIN, 2016, p. 451).

Com o seguro, as pessoas têm a possibilidade de investir suas conchas como precaução a possíveis futuros danos. Assim, cada um é responsável pelos bens que optaram e pelos seguros que adquiriram. Cabe a cada indivíduo, em sua liberdade e igualdade, optar por adquirir um determinado bem e, em decorrência dessa opção, ser responsável pelos resultados positivos ou danosos de suas escolhas. Por isso, Dworkin diz não haver motivo para negar, em nome da 
justiça distributiva, resultados pelos quais algum indivíduo possa ter menos do que aquele que foi precavido e contratou o seguro (DWORKIN, 2016, p. 455).

Dworkin destaca-se por enfrentar temas difíceis para a teoria da justiça, como a questão da deficiência física, como desdobramento do âmbito dos talentos naturais. Nesse sentido, por poder incapacitar indivíduos para uma livre escolha de projetos de vida quando comparados aos indivíduos que gozam de uma saúde plena, a deficiência física é concebida na teoria de Dworkin como uma desvantagem natural.

Neste ponto, para que a concepção de igualdade de recursos seja considerada justa, exige-se um sistema que produza desigualdades, como por exemplo, o custo diferencial de bens e oportunidades destinados àqueles com necessidades especiais. O importante é como fazer a diferenciação econômica de bens e oportunidades para alguns grupos de indivíduos, de modo que não ignore a base que fundamenta a igualdade de recursos (o leilão igualitário inicial) (OLIVEIRA, 2013, p.254-291).

Neste momento, Dworkin demonstra que tipo de concepção de justiça realmente subjaz sua teoria igualitária. Para isso, requer uma nova definição de liberdade, que não deve ser compreendida como sinônimo daquilo que é permitido, pois se trata de um conjunto de direitos distintos. A liberdade é um instrumento pelo qual se pode viabilizar um ideal de igualdade dentro de uma sociedade. E é deste modo que Dworkin traz para o debate a liberdade em companhia da igualdade de recursos (DWORKIN, 2016, p. 452).

Dessa forma, Dworkin contribui para a teoria do desenvolvimento com base em sua teoria da justiça principalmente por meio de sua tese de que o Estado deve tratar a todas as pessoas com igual respeito e consideração, por meio de uma distribuição equitativa de bens, que não anule a responsabilidade que cada pessoa possui de viver bem (2016, p. 254). Por fim, resta saber se é possível conquistar uma sociedade efetivamente amparada pelo valor da inclusão social a partir da disposição igualitária de recursos. Com a finalidade de oferecer uma resposta mais adequada a esta questão, Amartya Sen trabalha com a igualdade de capacitações.

\section{DESENVOLVIMENTO COMO JUSTIÇA EM AMARTYA SEN}

O presente tópico tem por objetivo trabalhar a perspectiva da teoria do desenvolvimento e da justiça na concepção de Amartya Sen, economista que se destacou no campo da filosofia política, recebeu o prêmio Nobel de Economia, foi um dos pensadores e idealizadores do Índice de Desenvolvimento Humano - IDH e grande estudioso do processo de 
desenvolvimento, não apenas na perspectiva de crescimento econômico, mas também das liberdades substantivas e capacidades dos indivíduos de terem uma vida de qualidade.

Amartya Sen inova por trazer um novo elemento para a teoria do desenvolvimento e da justiça, qual seja, a liberdade com base na abordagem das capacidades. Nesse sentido, aponta como novo desenvolvimento, concomitantemente ao crescimento econômico e à aferição de renda, também a qualidade de vida e a liberdade do indivíduo para fazer o que deseja (2011, p. 215).

Sen reconhece explicitamente a contribuição positiva de Rawls para a teoria da justiça, no entanto, ele também critica a perspectiva adotada por Rawls, com relação aos bens primários, porque se esta for a esfera na qual os indivíduos devem ser tratados como iguais, estar-se-á ignorando a importância da diversidade dos seres humanos. Segundo Sen, Rawls erra ao pensar que, se todas as pessoas aspiram aos mesmos princípios enquanto encobertos sob o véu da ignorância e, em seguida, um índice de bens primários tende a produzir liberdades semelhantes para todos, a esfera da igualdade negligencia o fato de que indivíduos distintos precisam de diferentes quantidades e diferentes tipos de bens para alcançar os mesmos níveis de bem-estar e desenvolvimento (2011, p. 279).

Segundo Sen, a perspectiva baseada em recursos desenvolvida por Dworkin possui a mesma característica de Rawls. A ideia centra-se no fato de que o foco sobre a capacidade tem o intuito de oferecer uma fórmula, no sentido de fornecer uma receita simples, ou mesmo um algoritmo para realizar exercícios empíricos nas comparações de bem-estar. Assim, abandonam totalmente o aspecto sobre o papel que cada indivíduo deseja desempenhar e o grau de liberdade que desfrutam para desenvolver. Portanto, este enfoque da igualdade seria um verdadeiro retorno à perspectiva do bem-estar. A questão primordial reside no fato de que um compromisso com uma ética sobre o indivíduo não é incompatível com uma ontologia que reconhece as conexões entre as pessoas, suas relações sociais e suas capacidades particulares.

No mesmo sentido, uma política pública direcionada a uma comunidade pode ser compatível com uma perspectiva igualitária, uma vez que a abordagem da capacidade abraça um individualismo ético sem assumir um individualismo ontológico (ROBEYNS, 2000). Isso esclarece que a abordagem sobre as capacidades pode ser complementada com outros elementos. Esses elementos são outras teorias ou percepções sociais relevantes, tais como as diferenças entre classes, gênero, sexualidade, deficiência física, raça, que, por sua vez, são baseados em processos sociais e contínuas descobertas sobre o ser humano. 
Portanto, as teorias de Rawls e de Dworkin, bem como a abordagem da capacidade, são capazes de refutar as críticas que as acusam de teorias demasiadamente individualistas. No caso da abordagem sobre a capacidade, não há uma dependência de um individualismo ontológico, sua preocupação envolve aquilo que é próprio a cada indivíduo, o princípio de cada pessoa como um fim em si mesmo (NUSSBAUM, 2000). Assim, nenhuma destas três teorias pode ser acusada disto.

Sen, em seu livro, “A ideia da justiça” (2011, p. 89), concentrou-se em modificar a perspectiva das capacidades, no sentido de igualdade como liberdade de funcionamentos, concebendo sua interpretação sobre a teoria da justiça. Por outro lado, Amartya Sen também foi acusado ou mal interpretado, com relação à sua abordagem sobre a capacidade, por conduzir uma teoria da justiça que intervém de maneira exagerada na vida particular dos indivíduos.

De maneira diversa, Dworkin argumenta que o governo deve se preocupar apenas com a distribuição justa dos recursos, e não com a capacidade das pessoas, pois esta se refere à vida privada de cada indivíduo. Segundo Dworkin, a ideia de que o governo deveria tomar medidas para trazer essa igualdade de capacidades, ou que as pessoas devem ser iguais em suas capacidades para atingir os estados sociais desejáveis, apesar de ser coerente, não é boa (2016, p. 203).

Dworkin, quando interpreta Amartya Sen, parte do pressuposto de que a questão central é o ideal moral da redistribuição governamental dos bens. Ademais, Dworkin acredita que políticas baseadas na perspectiva das capacidades podem ser paternalistas. Ao refletir sobre o paternalismo de uma forma geral, nota-se, no âmbito desta pesquisa, que, se qualquer governo preza pelos seus cidadãos, a rigor, qualquer sociedade possui algum grau de paternalismo, ainda que mínimo. Assim, a questão principal não é se a abordagem sobre a capacidade é paternalista, mas qual é o grau aceitável do paternalismo em um governo (OLIVEIRA, 2013, p.254-291).

Tendo por base a principal questão, qual seja, quanto um governo deve distribuir, a abordagem sobre as capacidades não pode ser criticada, pois argumenta a favor de uma distribuição concebida com base no que é intrinsecamente relevante para cada indivíduo. Assim, para Sen, o ponto principal é permitir que as pessoas desenvolvessem suas capacidades sem que haja impedimentos para esse desenvolvimento.

Assim, é diferente ter uma capacidade, desenvolvê-la e ter uma capacidade realizada. Sen desenvolve uma abordagem sobre as capacidades sem fazer nenhuma recomendação sobre distribuição de bens e recursos, mas deixa evidente que o âmbito das capacidades é o mais 
adequado para o diagnóstico social. Nesse sentido, alguns bens primários e recursos provavelmente serão a única maneira de ampliar o conjunto de capacidades das pessoas. Assim, Sen esclarece que a distribuição de determinados bens materiais é, sem dúvidas, o caminho para o alcance da liberdade de cada um (NUSSBAUM, 2003, 33-59).

As teorias da justiça e do desenvolvimento de Amartya Sen, bem como sua inovadora abordagem sobre a capacidade constituem os princípios fundamentais de uma abordagem que evoluiu os Relatórios de Desenvolvimento Humano - RDHs. Os RDHs, publicados anualmente para o Programa das Nações Unidas para o Desenvolvimento - PNUD desde 1990, utilizaram a abordagem de capacidade de Amartya Sen como base de análise dos desafios atuais do desenvolvimento. Ao longo dos anos, esses relatórios modificaram seus paradigmas. Atualmente, eles relacionam-se com desigualdades de gênero, redução da pobreza, governança, globalização e desenvolvimento sustentável (PNUD BRASIL, 2019).

O Índice de Desenvolvimento Humano - IDH - é um índice composto que reúne o Produto Interno Bruto - PIB per capita e as realizações em saúde e educação. O Índice de Pobreza Humana - HPI - mede a falta de acesso às três capacidades humanas centrais, uma renda decente, saúde e conhecimento. O Índice de Desenvolvimento de Gênero - IDG - tenta capturar o viés de gênero nas capacidades humanas centrais, com as mulheres geralmente pontuando muito pior do que os homens. Sob a abordagem neoliberal, o crescimento do PIB e do PNB formam os indicadores centrais de sucesso, juntamente com a inflação e vários indicadores de equilíbrio econômico, como o balanço de pagamentos e o superávit ou déficit de gasto público (JOLLY, 2003, 82-92).

A abordagem de Sen definiu o desenvolvimento humano como o processo de ampliar as funções e capacidades de uma pessoa para função, o leque de coisas que uma pessoa poderia fazer e ser em sua vida, expressos nos RDHs como escolhas em expansão (NUSSBAUM, 2003, 33-59).

Sen continuou a influenciar a evolução da abordagem do desenvolvimento humano, ampliando os conceitos básicos e as ferramentas de aferição, à medida que novos desafios políticos foram desenvolvimento sustentável (Programa das Nações Unidas para o Desenvolvimento 1994) igualdade de gênero (Programa das Nações Unidas para o Desenvolvimento, 1995), pobreza (Programa das Nações Unidas para o Desenvolvimento, 1997), consumo e desenvolvimento (Programa das Nações Unidas para o Desenvolvimento 
Eline Débora Teixeira

1998), direitos humanos (Programa das Nações Unidas para o Desenvolvimento 2000) e democracia (Nações Unidas Programa de Desenvolvimento 2002) (PNUD BRASIL, 2019).

Uma das grandes teses desenvolvidas por Sen e é que pensar sobre a teoria da justiça não é buscar criar modelos representacionais de sociedades perfeitas ou ideais. $\mathrm{O}$ transcendentalismo das teorias do contrato, como em Rawls, direciona-se exatamente a esse caminho criticado por Sen. Para o autor, questões de justiça e desenvolvimento envolvem, em primeiro plano, realizações sociais reais, ou seja, análises sobre situações de fato. De maneira geral, Sen realiza uma ampliação acerca da teoria da justiça e do desenvolvimento, construindo críticas profundas a Rawls e dando contribuições de grande valor para o presente debate, de maneira profunda e precisa na abordagem dos conceitos.

\section{CONSIDERAÇÕES FINAIS}

Em Aristóteles, observam-se contribuições para a teoria do desenvolvimento, com base em sua teoria da justiça, tendo em vista que a justiça não tratará do aspecto da moraridade privada e, sim, do aspecto equitativo, concernente à esfera pública, assim, aquilo que fere a equidade é também ilegal. Portanto, Aristóteles contribui para a atribuição de um significado objetivo para a teoria do desenvolvimento, ao definir o objeto central da teoria, qual seja, a garantia de equidade nas relações públicas da comunidade política.

Em Rawls, para se pensar a teoria da justiça, os elementos que fazem com que as pessoas sejam, de fato, diferentes, devem ser irrelevantes para que todos sejam tratados definitivamente como iguais. Assim, Rawls acredita que os princípios acordados entre as pessoas não serão distorcidos pelas contingências e nem provocarão desigualdades, quando advindos da posição original.

Rawls não privilegia os diferentes talentos naturais que as pessoas da sociedade possuem, nem abarca as particularidades de diferentes concepções de bem dos seus próprios cidadãos. Assim, com base na posição original, nos dois princípios de justiça e na imparcialidade, sua teoria é compatível com a atribuição de um significado objetivo para a teoria do desenvolvimento, com base na teoria da justiça, na medida em que afasta o utilitarismo da formação deste conceito, de forma a atribuir o valor de justo sobre o de bem.

Portanto, o fato de os indivíduos na posição original ignorarem tanto seus talentos quanto suas concepções de bem é o que possibilita a promoção de um conceito substancial de justiça. Os princípios da justiça são derivados da posição original, que tem por pressuposto a 
liberdade e a igualdade de todos os indivíduos. A teoria do desenvolvimento torna-se, nesse contexto, baseada em uma atitude racional constituída por dois princípios de justiça por ele apresentados.

Em Dworkin, a teoria da justiça que subjaz sua concepção igualitária requer uma nova definição de liberdade, que não deve ser compreendida como sinônimo daquilo que é permitido, pois se trata de um conjunto de direitos distintos. A liberdade ganha um novo significado, de instrumento pelo qual se pode viabilizar um ideal de igualdade dentro de uma sociedade. Assim, Dworkin traz para o debate da liberdade a questão central da igualdade de recursos.

Para Dworkin, a justiça será conquistada no momento em que todos os indivíduos alcançarem uma organização que proporcione a mesma capacidade aquisitiva entre os participantes do contrato. Com a igualdade de recursos é possível superar eventuais circunstâncias nas quais indivíduos poderiam naturalmente sofrer e necessitar de compensações político-sociais previstas em uma teoria da justiça inadequada.

Assim, Dworkin também contribui para a atribuição de um significado objetivo para a teoria do desenvolvimento, com base em seus estudos sobre a teoria da justiça, uma vez que acrescenta um novo significado para a liberdade, além de dar ênfase à questão central do dever do Estado de oferecer igual oportunidade de recursos por meio da igual consideração e respeito para com os cidadãos que compõem a sociedade.

Por fim, em Amartya Sen têm-se o auge da contribuição para a teoria do desenvolvimento com base nos estudos sobre a teoria da justiça. Uma das grandes teses desenvolvidas por Sen é que pensar sobre a teoria da justiça não é buscar criar modelos representacionais de sociedades perfeitas ou ideais. O transcendentalismo das teorias do contrato, como em Rawls, direciona-se exatamente a esse caminho criticado por Sen. Para o autor, questões de justiça envolvem, em primeiro plano, realizações sociais reais, ou seja, análises sobre situações de fato.

De maneira geral, Sen realiza uma ampliação acerca da teoria da justiça, construindo críticas profundas a Rawls e dando contribuições de grande valor para o presente debate, de maneira profunda e precisa na abordagem dos conceitos. Sen concentrou-se em modificar a perspectiva das capacidades, no sentido de igualdade como liberdade de funcionamentos, concebendo sua interpretação sobre a teoria da justiça. Com base na diferença entre ter uma capacidade, desenvolvê-la e ter uma capacidade realizada, Sen desenvolve uma abordagem 
sobre as capacidades sem fazer nenhuma recomendação sobre distribuição de bens e recursos, mas deixa evidente que o âmbito das capacidades é o mais adequado para o diagnóstico social.

Nesse sentido, alguns bens primários e recursos provavelmente serão a única maneira de ampliar o conjunto de capacidades das pessoas. Assim, Sen esclarece que a distribuição de determinados bens materiais é, sem dúvidas, o caminho para o alcance da liberdade de cada um. Essa abordagem sobre as capacidades, que alterou o significado de liberdade, constitui a principal contribuição de Sen para a teoria do desenvolvimento.

Portanto, com base nas contribuições de Aristóteles, Rawls, Dworkin e Sen, é possível conceber um significado objetivo para a teoria do desenvolvimento, que consiste em uma integração entre liberdade, igualdade e capacidade, sendo esses conceitos também possuidores de significado objetivo, desenvolvido pelos referidos autores em evolução cronológica, em que pese terem sofrido resignificações ao longo do tempo. Assim, a racionalidade comum destes conceitos integrados é trazer equidade para as relações intersubjetivas, sendo o Estado o agente garantidor desse desenvolvimento, com base no tratamento baseado em igual consideração e respeito às pessoas, bem como iguais recursos (igualdade material) destinados aos cidadãos, com base na abordagem das capacidades.

\section{REFERÊNCIAS}

ARISTÓTELES. Ética a Nicômaco. In: ARISTÓTELES. Tópicos, Dos argumentos sofísticos, Metafísica, Ética a Nicômaco, Poética. Tradução de Leonel Vallandro e Gerd Bornheim. São Paulo: Abril Cultural, 1973. p. 245-442.

BARBOSA, Evandro. Deontologia imparcial contratualista: sobre a possibilidade de um procedimento autojustificado para a construção de princípios de justiça. Orientador: Thadeu Weber. Tese (Doutorado em Filosofia), Programa de Pós-Graduação em Filosofia, PUCRS, Porto Alegre, 2011.

BENTHAM, Jeremy. Uma introdução aos princípios da moral e da legislação. $2^{\mathrm{a}}$ ed. Trad. Luiz João Baraúna. São Paulo: Abril Cultural, 1979.

BROADIE, Sarah. In : Aristotle. Nicomachean Ethics. Trasl. C. Rowe. Philosophical introduction and commentary. Oxford: Oxford University Press, 2002, pp. 09-91.

DWORKIN, Ronald. A virtude soberana: a teoria e prática da igualdade. São Paulo: Martins Fontes, 2016.

DWORKIN, Ronald. O Império do Direito. São Paulo: Martins Fontes, 2014. 
HARVEY, David. O neoliberalismo: história e implicações. Tradução: Adail Sobral e Maria Stela Gonçalves. 5. ed. São Paulo: Edições Loyola, 2014, p. 75.

JOLLY, Richard. Human Development and Neo-Liberalism - Paradigms Compared. Sakiko Fukuda-Parr and A.K. Shiva Kumar(eds) Readings in Human Development, New Delhi, Oxford, 1.8, 82-92, 2003.

KANT, Immanuel. À paz perpétua. Trad. Marco Zingano. Porto Alegre, RS: L\&PM, 2010.

LOCKE, J. Segundo Tratado sobre o Governo. Traduções de Anoar Aiex e E. Jacy Monteiro, $3^{\text {a }}$ ed. São Paulo: Abril Cultural, 1983.

MILL, John Stuart. Utilitarianism. Auckland, New Zealand: The Floating Press, 2009.

NOVAIS, Alinne Arquette Leite Novais. A justiça social em Aristóteles, Kant e Rawls.

Revista de Direito Constitucional e Internacional. vol. 46/2004, p. 203/232. jan/mar. 2004.

NUSSBAUM, Martha. Capabilities as fundamental entitlements: Sen and Social Justice.

Feminist Economics, 9 (2/3): 33-59, 2003.

OLIVEIRA, Fabio Alves Gomes de. GOMES, Jacqueline de Souza. O conceito de igualdade na filosofia política contemporânea: um debate entre Rawls, Dworkin e Amartya Sen. Revista de Filosofia Moderna e Contemporânea. Brasília, vol.1(2), dez. 2013, p.254-291.

PNUD BRASIL. Disponível em: http://www.br.undp.org/content/brazil/pt/home/. Acesso em: 30 jan. 2019.

RAWLS, John. Uma teoria da justiça. Tradução: Jussara Simões. Revisão técnica e da tradução: Álvaro de Vita. São Paulo: Martins Fontes, 2016.

ROBEYNS, Ingrid An Unworkable Idea or a Promising Alternative? Sen's Capability Approach Re-examined. In: Center for Economic Studies Discussion. Leuven, 2000.

RODRIGUES, Leo Peixoto; NEVES, Fabrício Monteiro. Niklas Luhmann: a sociedade como sistema. Porto Alegre: Edipucrs, 2012.

ROUANET, L. P. Rawls e o enigma da justiça. São Paulo: Unimarco Editora, 2002.

SEN, Amartya. A ideia de justiça. Tradução: Denise Bottmann e Ricardo Doninelli Mendes. São Paulo: Companhia das Letras, 2011.

SEN, Amartya. Desenvolvimento como liberdade. São Paulo: Companhia das Letras, 2010.

SILVEIRA, Denis Coitinho. Complementaridade entre uma ética das virtudes e dos princípios na teoria da justiça de Aristóteles. Veritas, Porto Alegre, v. 52, n. 02, p. 35-55, jun. 2007.

TRUBEK, David M.; GALANTER, Marc. Acadêmicos auto-alienados: reflexões sobre a crise norte-americana da disciplina "Direito e Desenvolvimento" (1974). Revista Direito GV, 
[S.1.], v. 3, n. 2, p. 261-304, jul. 2007. ISSN 2317-6172. Disponível em: http://bibliotecadigital.fgv.br/ojs/index.php/revdireitogv/article/view/35190/33994. Acesso em: 27 jan. 2019. 